\title{
China's Cadre Transfer Policy toward Tibet in the 1980s
}

\author{
YASHENG HUANG \\ University of Michigan
}

There is a crucial distinction between population migration and personnel transfer. The latter is a systematic and deliberate government program to move people from one location to another. Such a movement can be induced by the financial or non-financial incentives the government sets up specifically to accomplish such an objective and/or it can be directly organized by the government via administrative methods. China's transfer policy toward Tibet is implemented on the basis of both incentives and administrative compulsion. Migration, on the other hand, refers to a spontaneous movement of people from one place to another. There are complex causes for such a movement, including economic opportunities and family-related considerations. Even though Chinese migration to Tibet has caused great resentment in Tibet, it should be recognized that such a movement of people has been a result of a nationwide relaxation of economic control rather than a result of a deliberate government program specifically aimed at Tibet. ${ }^{1}$ As such, migration is a lesser indication of government intentions toward Tibet than is personnel transfer policy specifically designed for Tibet.

This article focuses on the personnel transfer policy of the Chinese government in the 1980 s and on the politically and strategically sensitive personnel (i.e., cadres) transferred to Tibet. First, the reason for this focus has to do with the fact that the Chinese transfer policy

AUTHOR'S NOTE: I wish to thank Jing Jun for a stimulating conversation on the subject and for sharing his own research and sources. Nancy Hearst proofread the paper and provided excellent editorial assistance. In addition, the author thanks Fu Jun, Melvyn Goldstein, and Kenneth Lieberthal for their comments on earlier drafts. All faults, however, are those of the author. 
in the 1980s mainly pertained to cadres. As I will show below, in the 1980 s the Chinese central government carefully limited transferees to more educated and technical personnel. Second, there is more information available on cadres than there is on ordinary citizens. Third, focusing on cadres is a more meaningful line of research since cadres-not ordinary workers-presumably control vital political and strategic positions; whether these positions are increasingly controlled by Chinese sent from other parts of the country is a more indicative measure of the intentions of the government.

To ensure reliability, I have purposely avoided official and public statements. Instead, I base my analysis solely on three sources of primary information. One is a collection of government documents, consisting of thirteen volumes, titled Renshi gongzuo wenjian xuanbian (Selections of Documents on Personnel Work; Ministry of Labor and Personnel, 1984, 1986; Ministry of Personnel, 1988, 1990). This collection deals with a wide range of issues related to personnel management: from recruitment, promotion, salary policy, and cadre transfer to rehabilitation, retirement, pension policy, and so on. All of the documents dealing with Tibet fall into the category of "cadre transfer" (diaopei). The second source of information is a book put out by the Department of Rotation and Transfer under the Ministry of Personnel, titled Liudong diaopei gongzuo zhinan (Guidebook on Rotation and Transfer Work; Ministry of Personnel, 1991). The book is intended for government officials who handle personnel issues and explains the terms, the history, and the various policy points related to rotation and transfer work. The third source is an unpublished paper prepared by researchers at the Institute of Sociology of Beijing University (1989). The paper contains statistics on the total number of cadres in Tibet, the number of cadres transferred into and out of Tibet between 1981 and 1987, and the ethnic composition of cadres in Tibet for selected years. These statistics come from primary sources, such as documents at the Bureau of Personnel in the Tibetan government.

The contents of the two document collections should be considered credible because they are restricted in circulation (neibu faxing) and, in all likelihood, they were marked "classified" at the time of their issue. Although China's secrecy law of 1988 does not have a neibu (literally "internal") category, ${ }^{2}$ neibu documents are conventionally considered quasi-secret (Jia and Peng, 1989: 69). Given this status and 
the fact that the collections are not limited to documents on Tibet, there is no reason to believe that the rationales for the transfer policy and the numbers of the transferees given in these documents were designed to achieve propaganda purposes; nor is there any reason to believe that the statistics contained in the unpublished paper were aimed at achieving any propaganda purposes. The research was an independent project undertaken by the researchers at the Institute of Sociology at Beijing University. ${ }^{3}$

Because of the depth of emotions the Tibetan question generates and because of the reluctance of the Chinese authorities to release information, debate on Chinese rule in Tibet is often long on passion and political partisanship but short on evidence. In this respect, any research based on hard data should be particularly welcome. Although it is possible that evidence released in the future may contradict the findings here, based on the relatively systematic data currently available, one must conclude that the Chinese cadre transfer policy toward Tibet in the 1980s appears to be quite close to what the Chinese government publicly claims - that it has been limited in scale and that its main purpose is to provide economic assistance.

This article portrays various aspects of the government's transfer policy as described in the aforementioned documents by discussing the procedures and methods of transferring Chinese to Tibet as well as its explicit and implicit purposes. It also looks at transfers out of Tibet. Finally, it considers the processes and mechanisms for transferring people in both directions in light of the debate in the international community about Chinese transfer policy toward Tibet.

\section{IN-TRANSFERS}

First, some definitions are necessary. The word "cadre" (ganbu) here follows its standard Chinese bureaucratic usage, that is, it refers to two types of personnel. One would be those who perform public functions in a political or bureaucratic capacity. This usage is akin to the concept of government officials or civil servants in other countries. The other type of personnel consists of those who hold clerical positions but who formally fall under the official nomenklatura list. Examples of this type include teachers, technicians, managers, and so 
on. ${ }^{4}$ The word "transfer" (diaopei) refers to a routine Chinese bureaucratic practice whereby a cadre is transferred from one administrative jurisdiction (lishu guanxi) to another. The specific methods can include a change in the position or the workplace. Such transfers can be effected for either work-related or personal reasons (Ministry of Personnel, 1991: 251). The term "inland regions" (neidi) refers to China proper, although this geographic concept is rather loose because it can also refer to areas such as Xinjiang, Gansu, and Qinghai in the context of this article.

\section{PROCEDURES AND INCENTIVES}

The Chinese government's program to dispatch cadres to Tibet is part of its general program of sending cadres to "border and remote regions" (bianyuan diqu), although in important aspects transfers to Tibet seem to be more centrally supervised. There are certain established practices and procedures by which this program is enforced. These involve the classification of border and remote regions according to the levels of their associated hardship, the system of financial and non-financial incentives to encourage transfers, and the term of service.

Border and remote regions are defined by the Chinese government according to geographic, natural, political, and economic criteria (see Ministry of Labor and Personnel, 1983). The geographic criterion mainly refers to the fact that these regions are located along China's borders; natural conditions pertain to the high altitudes and low temperatures of these regions. Political and economic criteria, on the other hand, are devised to take into account ethnic factors and the level of poverty. An application of these criteria yields a formal division of border and remote regions into three categories, with the thirdcategory regions having the most difficult conditions according to the specified criteria. ${ }^{5}$ All of Tibet is classified as a third-category region (Ministry of Personnel, 1991: 177).

A system of financial incentives has been established to encourage cadres-and especially technical specialists-to work in the border and remote regions. These incentives include higher retirement pensions and the enjoyment of special benefits provided by the provincial governments of these regions (see Ministry of Labor and Personnel 
and State Nationalities Affairs Commission, 1983: 361-362). For Tibet, it seems that the levels and the forms of these incentives are spelled out in greater detail centrally and, as a total package, they may be greater than similar incentives for other regions. The main reason why Tibet seems to be treated differently and more centrally is not only the presence of ethnic tensions in the region; an equally or more important reason relates to the harshness of living conditions in Tibet and, therefore, its presumed unattractiveness to Chinese. This explanation is consistent with the fact that, in a number of documents, the central government lumps Tibet together with Qinghai, another province with similarly difficult living and environmental conditions (but free of any ethnic tensions), and discusses cadre transfer policies for these two provinces separately from other provinces that also qualify as hardship posts. ${ }^{6}$

The incentives offered to those who are transferred to work in Tibet are of two types. First, Chinese transferees receive the same salary treatment as cadres with the same administrative ranks already working in Tibet (Department of Organization, Ministry of Labor and Personnel, 1983a: 358). This can mean significant income supplements when moving to Tibet. There are two sources of these income supplements. One is that Tibet is in the highest - the eleventh"salary zone" (gongzi qu); the level of salary in the eleventh salary zone is indexed to the salary level in the sixth salary zone. The method of calculation is to take the level of the sixth salary zone as the base and then add $13.04 \%$ of that base as the supplement. The second source of income supplements consists of a cost-of-living adjustment, which may vary in the same salary zone. For Lhasa, it is $52 \%$ of the salary level, as determined by the eleventh salary zone method outlined above. ${ }^{7}$ Taking the two sources of the income supplements together, a cadre moving from a sixth salary zone to Lhasa can receive an income supplement equivalent to $71.82 \%$ of his/her original salary. ${ }^{8}$

Second, the Tibetan government also has established financial and non-financial incentives specifically aimed at technical cadres. Children of technical cadres who have worked in Tibet for a long time are given priority in job assignments and requests for urban residency status. Monthly allowances also are given in addition to salary (inclusive of the supplements); these allowances apparently vary from region to region (Tibet is divided into four regions based on the level 
TABLE 1: Monthly Allowances and Regional Categories in Tibet

\begin{tabular}{lccc}
\hline & \multicolumn{3}{c}{ Administrative Ranks } \\
\cline { 2 - 4 } Regional Categories & Assistant Level & Middle Level & Senior Level \\
\hline First & 10 & 15 & 20 \\
Second & 15 & 20 & 25 \\
Third & 20 & 25 & 30 \\
Fourth & 25 & 30 & 35 \\
\hline
\end{tabular}

NOTE: Units are presented in yuan.

SOURCE: Ministry of Personnel (1991: 183).

of "hardship"; Ministry of Personnel, 1991: 182-183) (see Table 1). Because the income supplements are not tied to the size of one's income, this system enhances the proportionate income-augmenting effect of moving across different regional categories, as compared with moving across different administrative ranks within the same regional category.

The term of service in Tibet is fixed. For Party and government cadres (dangzheng ganbu), it is five years; for technical cadres (zhuanye jishu ganbu), three years (Ministry of Personnel, 1991: 73). That the term of service is fixed can be considered another form of incentive in the sense that it guarantees transferees the right to return to their original residencies. To accentuate this right, transferees' residency status (hukou) and their institutional affiliation are not affected by the transfer (Department of Organization and Ministry of Labor and Personnel, 1983a: 358).

\section{PURPOSES}

The transfer of cadres to border and remote regions was suspended for ten years during the Cultural Revolution; it was resumed only after the Third Plenum of the Eleventh Central Committee in December 1978 (Ministry of Personnel, 1991: 72). The first large, organized in-transfer in the post-Mao era apparently occurred in 1979 when about 3,000 cadres were sent to Tibet. A full explanation is not available for this sudden infusion of Chinese transferees; the text of the document issued by the Department of Organization in 1979 authorizing this transfer is not included in Renshi gongzuo or in Liudong diaopei. ${ }^{9}$ The most plausible conjecture is that the policy on 
transferring cadres into Tibet and the policy on transferring cadres out of Tibet were implemented in conjunction with one another: the increase in the number of people transferred to Tibet in 1979 was probably to replenish the stock of Chinese cadres in anticipation of the large-scale, three-year withdrawal of Chinese cadres from Tibet that the central government was to implement in 1980, 1981, and 1982 (discussed below.) Indeed, in 1980, 3,000 cadres were withdrawn from Tibet (Department of Organization, 1980: 119).

Other evidence supporting this interpretation is contained in a 1980 Department of Organization document, which enunciates a number of specific measures to transfer cadres to inland areas. The document declares: "Based on the thrust of the 1979 document issued by the Department of Organization, there will be 3,000 cadres transferred to inland regions for job reassignments before the end of July this year" (Department of Organization, 1980: 119).

A more general purpose behind the transfer program in the $1980 \mathrm{~s}$ was to promote Tibet's economic development by infusing technical expertise into the region. Evidence for this can be seen in the policy orientation of stressing technical personnel as laid out in the government documents, and also in the type of central government agencies that have been involved in organizing the transfer activities. In addition, a professional profile of those transferred to Tibet provides further evidence.

In a 1980 report to the Party Center and the State Council, the Tibetan Party committee and government made a request for more doctors and teachers, as well as for more technicians for new investment projects (Party Committee and People's Government of the Tibetan Autonomous Region, 1980: 123). The central policy to send technical personnel to Tibet was formed in 1980; those transferred were to be "few in number but high in quality" (shao er jing). This emphasis implied that political functionaries were to be limited to a level that was "absolutely necessary" (biyaode). Furthermore, ordinary workers were not encouraged to move to Tibet (Ministry of Personnel, 1991: 73). In 1983, the Department of Organization and the Ministry of Labor and Personnel (1983a: 358) re-affirmed this policy orientation:

Selecting and dispatching cadres to Tibet must be handled strictly and should be carried out on the principle that they should be few in 
TABLE 2: Government Agencies Involved in Cadre Transfers to Tibet in the 1980s

\begin{tabular}{ll}
\hline Year & Government Agency Involved in Sending Cadres \\
\hline 1981 & State Meteorological Administration \\
& Ministry of Education \\
& Ministry of Health \\
1982 & Ministry of Water Resources and Electric Power \\
& Ministry of Posts and Telecommunications \\
& Ministry of Geology and Mineral Resources \\
& State Meteorological Administration \\
& People's Bank of China \\
& Ministry of Education \\
& Ministry of Health \\
& Ministry of Foreign Affairs \\
& Ministry of Communications \\
& State Planning Commission \\
& State Economic Commission \\
& Ministry of Public Security \\
& Ministry of Agriculture, Animal Husbandry, and Fisheries \\
& Ministry of Forestry \\
& Department of Propaganda \\
\hline
\end{tabular}

SOURCES: Ministry of Personnel (1991: 73) and Department of Organization and Ministry of Labor and Personnel (1983a: 357-358).

number but high in quality. Cadres to be transferred to Tibet must be in the most urgent demand in Tibet; those not in need now should be delayed being sent in. [To ascertain this demand,] investment projects and the people to be transferred must be screened and determined on a case-by-case basis.

The emphasis on technical personnel means that government agencies sending transferees tend to be specialized and technical ones. This is readily seen in Table 2, which shows an overwhelming dominance of technical agencies involved in the several rounds of transfers in the 1980s.

A more direct measure of the purpose of the transfer program is the composition of those cadres who are transferred to Tibet. Statistical breakdowns by occupations are available for the 414 cadres transferred to Tibet in 1988. Table 3 gives the number of transferee cadres and their respective percentages. The largest number of transferees are involved in economic management $(32.61 \%)$; next are those in the tourist industry $(26.57 \%)$. When transferees are divided into control- 
TABLE 3: Occupational Composition of Cadres Transferred to Tibet in 1988

\begin{tabular}{lcc}
\hline & Number of Persons & Percentages \\
\hline Party and government & 54 & 13.04 \\
Public security & 21 & 5.07 \\
Tourism & 110 & 26.57 \\
Economic management & 135 & 32.61 \\
Foreign affairs & 16 & 3.86 \\
Finance & 54 & 13.04 \\
Auditing & 7 & 1.69 \\
Urban planning & 9 & 2.17 \\
Labor & 8 & 1.93 \\
Total & 414 & 99.98 \\
\hline
\end{tabular}

NOTE: The percentages do not add up to 100 because of rounding.

SOURCE: Department of Organization and Ministry of Personnel (1988).

related and non-control-related purposes in terms of the functions they perform (control-related cadres are classified as those who perform Party, government, and public security functions), then it is clear that control-related cadres are in a decided minority. Control-related cadres are only about $18 \%$ of the total; $82 \%$ of transferees perform economic and technical functions. ${ }^{10}$

\section{OUT-TRANSFERS}

In the 1980s, the Chinese central government adopted a policy of systematically and periodically withdrawing Chinese cadres from Tibet. In this section, I will discuss the characteristics of, and the rationales for, these out-transfers.

\section{CHARACTERISTICS}

There appear to have been five large-scale withdrawals in the 1980s: in 1980,1981, 1982, 1983, and 1989. The withdrawal program in the early 1980s was initially envisioned to be completed in three years, from 1980 to 1982 (Party Committee and People's Government of the Tibetan Autonomous Region, 1980: 124). Because of unspecified complications, however, the program was not completed until 
1983. Another idea that was originally envisioned, during the last round of wholesale withdrawals in 1983 , was to establish a routine procedure to handle cadre out-transfers on a case-by-case basis in lieu of a centrally supervised program. However, as I will show later, a series of unforeseen events led to the resumption of wholesale withdrawals in 1989.

The methods of transfer have followed the routines established in the earliest rounds. Throughout, one principle has been enforced quite consistently, that is, transferred cadres should return to their places of origin. The geographic distribution of returnees was released for the 1983 and 1989 rounds and is reproduced in Table 4; the application of the aforementioned rule enables us to deduce a pattern by which cadres are dispatched to Tibet.

The first salient characteristic is the relative insignificance of central government personnel in staffing administrative and political positions in Tibet; in 1983, only twenty-five cadres out of 2,705 returned to central Party and government agencies (zhongyang guojia jiguan) and, in 1989, the figure was only three. That in-transferees consist primarily of provincial-level officials implies that the in-transfer program involves horizontal transfers (pingdiao), that is, transfers occur across regions but at the same level of the bureaucratic hierarchy. ${ }^{11}$

A second noteworthy feature is there appears to be a regional pattern: provinces such as Hebei, Jiangsu, Shandong, Henan, Sichuan, and Shaanxi have consistently sent and therefore received a large number of cadres. Except for Sichuan, which may bear a disproportionate burden due to its proximity to Tibet, it is not possible to pinpoint the reasons why some provinces have consistently sent more cadres to Tibet than others.

A principle that has guided the transfer policy concerns the family members of the recalled cadres. The spouse and children of recalled cadres are known as "accompanying transfer personnel" (suidiao renyuan) (Party Committee and People's Government of the Tibetan Autonomous Region, 1980: 124). Significantly, the policy of allowing children to leave with their parents applies to transferees from Qinghai only conditionally: children without a regular job in Qinghai are allowed to leave with their parents (Department of Organization, 1979: 117). The differential policy most likely reflects differences in 
TABLE 4: Geographic Distribution of Chinese Returnees, 1983 and 1989

\begin{tabular}{|c|c|c|}
\hline & 1983 & 1989 \\
\hline \multicolumn{3}{|l|}{ Central Party and } \\
\hline Anhui & 62 & 81 \\
\hline Beijing & 19 & 45 \\
\hline Fujian & 10 & 5 \\
\hline Gansu & 71 & 125 \\
\hline Guangdong & 21 & 18 \\
\hline Guangxi & 9 & 5 \\
\hline Guizhou & 13 & 10 \\
\hline Hainan & N/A & 1 \\
\hline Hebei & 126 & 160 \\
\hline Heilongiiang & 7 & 9 \\
\hline Henan & 218 & 381 \\
\hline Hubei & 33 & 38 \\
\hline Hunan & 68 & 49 \\
\hline Inner Mongolia & 7 & 4 \\
\hline Jiangsu & 138 & 181 \\
\hline Jiang $x i$ & 5 & 11 \\
\hline Jilin & 10 & 5 \\
\hline Liaoning & 30 & 43 \\
\hline Ningxia & 0 & 0 \\
\hline Qinghai & 15 & 19 \\
\hline Shaanxi & 109 & 196 \\
\hline Shandong & 153 & 324 \\
\hline Shanghai & 22 & 38 \\
\hline Shanxi & 30 & 81 \\
\hline Sichuan & 1,445 & 1,603 \\
\hline Tianjin & 11 & 18 \\
\hline Xinjiang & 3 & 3 \\
\hline Yunnan & 16 & 15 \\
\hline Zhejiang & 29 & 36 \\
\hline \multicolumn{3}{|l|}{ Total number } \\
\hline of returnees & 2,705 & 3,507 \\
\hline
\end{tabular}

SOURCES: Department of Organization and Ministry of Labor and Personnel (1983b: 171), and Department of Organization, Ministry of Personnel, and Ministry of Labor (1989: 232-233).

motivations behind the transfer policies for Tibet and Qinghai. In the case of Qinghai, the impetus is compensatory in nature - to grant home returns to those who have served in a "hardship post" for a long time; in the case of Tibet, the motive is to maximize the number of Chinese returnees on account of potential ethnic tensions in the region. 
Policy documents also give statistical information on the scale of the out-transfer policy for a number of years during the 1980s. Table 5 mainly relies on the Institute of Sociology (1989) for its data; in this section, however, I will draw on policy documents as sources of information to assess the scale of the out-transfer policy.

In general, the out-transfer policy includes both cadres and workers, with workers usually outnumbering cadres by a significant margin. In $1983,2,705$ cadres were withdrawn along with 3,906 workers (Department of Organization and Ministry of Labor and Personnel, 1983b: 171); in 1989, there were 3,507 cadres and 7,610 workers withdrawn (Department of Organization, Ministry of Personnel, and Ministry of Labor, 1989: 232). In 1980 and 1982, both cadres and workers were withdrawn but the number of the workers was not disclosed; the only clue is given in a document (Department of Organization and Ministry of Labor and Personnel, 1983b: 167) that mentions that the scale of the out-transfers in 1980 and 1982 was larger than that for 1983.

The real implication of the out-transfer policy actually is greater than the above numbers suggest. This is because the out-transfer policy not only includes cadres and workers who are recalled to inland regions (neidiao), but also those who are resettled (anzhi) in inland regions upon retirement. In 1989, 10,667 cadres and workers were withdrawn; in addition, 4,156 retired cadres and workers were resettled in inland regions (1,710 cadres and 2,446 workers), resulting in a total of 14,823 cadres and workers being transferred out of Tibet (Department of Organization, Ministry of Personnel, and Ministry of Labor, 1989: 232).

\section{RATIONALES}

Two rationales are associated with transferring cadres out of Tibet, both of which are closely connected with the ethnic tensions in the region. The first is to increase gradually the proportion of ethnic Tibetan cadres in local Party and government agencies; such a desire motivated the large-scale withdrawals of cadres in the late 1970s and the early 1980s. In a report to the Party Center and the State Council, the Tibetan authorities set the goal of increasing the proportion of the Tibetan non-production-related cadres (tuochan ganbu) ${ }^{12}$ to more than 
two thirds in two to three years (Party Committee and People's Government of the Tibetan Autonomous Region, 1980: 123). The effect of this ethnic "quota" falls most heavily on those cadres who perform political functions. The aforementioned report, for example, treats political and technical cadres very differently: all political cadres, it declares, except for the few key personnel, should leave, whereas technical cadres are allowed to leave only if they meet certain specified conditions. ${ }^{13}$ Thus the transfer policy is not only to reduce the Chinese presence in general, but particularly to reduce the Chinese political presence. ${ }^{14}$

How successful was the central government in accomplishing this goal? As we have noted, the goal that the Tibetan authorities set out to achieve by 1983 was that more than two thirds of the cadres in Tibet were to be of Tibetan origin; in reality, a figure of $58 \%$ was attained (calculated from Institute of Sociology, 1989: 5 and 7). As a whole, the 1980 s witnessed a gradual decrease in the number of the Chinese cadres; in 1978, about $55.4 \%$ of the cadres in Tibet were Chinese; by 1987, it was down to $38.65 \%$ (Institute of Sociology, 1989: 5).

The second objective of withdrawing Chinese cadres from Tibet is similar in that it seeks to reduce the Chinese political presence in Tibet, but the specific impetus was a reaction to several large protests in Lhasa and the intention was to defuse ethnic tensions. This motive lay behind the withdrawal of Chinese cadres in 1989.

On March 31, 1989, the Department of Organization, Ministry of Personnel, and Ministry of Labor (1989) jointly issued a document that announced the decision to withdraw 10,667 Chinese cadres and workers from Tibet. The origin of this decision, however, can be traced to March 1988 when the Politburo Standing Committee met and instructed that the withdrawal program be sped up.

The program to return Chinese cadres and workers to, and settle them in, the inland regions was first raised as early as March last year. At that time, the Politburo Standing Committee, in studying to further stabilize the situation in Tibet, pointed out that those personnel who were transferred to Tibet and who are outside the nomenklatura as a result of system reforms must be resettled as soon as possible. After Tibet proposed a course of action to return the personnel to the inland regions, at the end of last year, the Politburo Standing Committee again studied the transfer and settlement of Chinese cadres and workers and in- 
structed that this task be done well and difficulties be overcome to speed up the implementation [Department of Organization, Ministry of Personnel, and Ministry of Labor, 1989: 228; emphasis added].

Several large-scale protests in Lhasa occurred around the time the Politburo met to deliberate this issue and the time the aforementioned document was issued: October 1, 1987, March 5, 1988, and again March 5, 1989. The extremely close coincidence between these protests and the timing of the Politburo meetings and of the eventual decision suggests a link between the protests and the decision to withdraw more than 10,000 Chinese cadres and workers in 1989. In addition, the unforeseen protests in Lhasa apparently forced the hand of the central government and caused it to reverse a decision it had made only a few months earlier. On July 29,1987 , four months before the Politburo proposed another round of transfers, the Department of Organization and Ministry of Labor and Personnel (1987) issued a policy document, setting forth the population transfer as "routine work" that should proceed henceforth on a case-by-case basis. The document gives no indication that another large-scale round of outtransfers was being contemplated.

There was also a sense of urgency associated with the implementation of the withdrawals. The Department of Organization, the Ministry of Personnel, and the Ministry of Labor (1989: 228) demanded a speedy implementation: those units to receive less than 400 outtransferees were directed to complete the task by the end of the year, whereas those receiving more than 400 , if they encountered difficulties, were to complete the task in 1989 and 1990. It is a reasonable conjecture that the riots in Lhasa not only provided the impetus for reversing the original decision not to withdraw cadres on a wholesale scale, but also added a sense of urgency to implementation of the withdrawals.

\section{MAGNITUDE OF TRANSFERS INTO TIBET}

The magnitude of personnel transfers into Tibet must take into account the number of people the central government has sent to Tibet as well as the number of people the central government has withdrawn 
TABLE 5: Total Number of Cadres and Net Transfers, 1979 to 1988

\begin{tabular}{lccccc}
\hline & $\begin{array}{l}\text { Total Number } \\
\text { of Cadres } \\
\text { in Tibet }\end{array}$ & $\begin{array}{c}\text { Number of } \\
\text { In-transferees }\end{array}$ & $\begin{array}{c}\text { Number of } \\
\text { Out-transferees }\end{array}$ & $\begin{array}{c}\text { Net } \\
\text { In-transfers }\end{array}$ & $\begin{array}{c}\text { Net In-transfers } \\
\text { as Percentage } \\
\text { of All Cadres } \\
\text { in Tibet }\end{array}$ \\
\hline 1979 & N/A & 3,000 & N/A & N/A & N/A \\
1980 & 59,780 & N/A & 3,000 & N/A & N/A \\
1981 & 54,029 & 1,574 & 8,235 & $-6,661$ & -12.33 \\
1982 & 52,693 & 1,049 & 4,961 & $-3,912$ & -7.43 \\
1983 & 45,821 & 1,726 & 2,617 & -891 & -1.94 \\
1984 & 51,587 & N/A & N/A & N/A & N/A \\
1985 & 52,028 & 1,361 & 1,855 & -494 & -0.95 \\
1986 & 52,311 & 537 & 487 & 50 & 0.096 \\
1987 & 53,847 & 773 & 697 & 76 & 0.147 \\
1989 & N/A & N/A & 3,507 & N/A & N/A \\
\hline
\end{tabular}

SOURCES: Institute of Sociology (1989: 7), Department of Organization (1980: 119), and Department of Organization, Ministry of Personnel, and Ministry of Labor (1989: 232).

*Includes both Chinese and Tibetan cadres.

from Tibet; an accurate measure should be the net in-transfers, that is, the number of people transferred to Tibet minus the number of the people that were withdrawn in a given year. During the 1980s, has the central government, on average, transferred more cadres into Tibet than it has transferred out? If the central government has transferred more cadres into Tibet, then obviously the net in-transfers should be positive; otherwise, they should be negative.

Although statistics are sketchy, there are some available for certain years; in particular, the Institute of Sociology (1989) gives the most detailed statistics on the total number of cadres in Tibet and the number of cadres transferred into and out of Tibet between 1981 and 1987. In the 1980s, for four out of six years for which statistics are available, the central government transferred more cadres out of Tibet than it transferred in. This is seen in column five of Table 5, which shows the net in-transfers to be negative for $1981,1982,1983$, and 1985. Net in-transfers were positive in 1986 and 1987 , but only modestly as those transferred to Tibet outnumbered those transferred out by only fifty and seventy-six, respectively. Although no statistics are available on the number of cadres transferred to Tibet in 1989, given the large 
TABLE 6: Party-State Intensity as Measured by the Ratio of Party and Government Cadres to the Population of Tibet, 1981 to 1987

\begin{tabular}{llllllll}
\hline & 1981 & 1982 & 1983 & 1984 & 1985 & 1986 & 1987 \\
\hline $\begin{array}{l}\text { Cadres as } \\
\text { percentage of } \\
\text { total population }\end{array}$ & 3.23 & 2.91 & 2.78 & 2.37 & 2.62 & 2.58 & 2.59 \\
\hline
\end{tabular}

SOURCES: Calculated from the number of cadres from Institute of Sociology (1989), and Tibetan population figures from Statistical Bureau of Xizang Autonomous Region (1993).

number of cadres withdrawn that year $(3,507)$, the net in-transfer also could have been negative.

The scale of withdrawal of cadres from Tibet is significant. In 1981 alone, more than 8,000 cadres were withdrawn, which amounted to more than $12 \%$ of the total cadres in Tibet after deducting the number of transferees to Tibet (column six of Table 5). Looked at another way, in 1981, after deducting the number of in-transferees, almost $22 \%$ of all Chinese cadres working in Tibet were transferred out. ${ }^{15}$ The scale of out-transfers was reduced progressively to only about $1 \%$ in 1985 , signaling the completion of the government's program of withdrawing Chinese cadres by the mid-1980s. The withdrawals on this scale have reduced the ratio of cadres to the total population of Tibet. Some social scientists have used the ratio of cadres to total population to measure "party-state intensity"; ${ }^{16}$ as seen in Table 6, the ratio has declined from $3.23 \%$ in 1981 to $2.59 \%$ in 1987 .

\section{CONCLUSION}

China's cadre transfer policy with respect to Tibet in the $1980 \mathrm{~s}$ seems to have been targeted and selective: it focused on educated and technical personnel, and purposely restricted the transfer of political functionaries and ordinary workers. Also in the 1980s, the Chinese government pursued an equally conscious and systematic policy of withdrawing a large number of Chinese cadres from Tibet, especially those who performed political functions. It should be stressed that when the number of out-transferees is taken into account, the number of the net in-transferees is small and for the bulk of the $1980 \mathrm{~s}$ 
more cadres were withdrawn from Tibet than those transferred to Tibet.

First of all, the transfer policy seems to have grown from the government's sensitivity to Tibetans' reactions to the Chinese presence in the region. The policy of reducing the Chinese political presence in Tibet is calculated either to preempt future ethnic conflicts, as in the case of the in-transfer programs in the late 1970s and the early 1980s, or to appease Tibetan sentiment in the wake of protests against Chinese rule, as in the case of the withdrawal program in 1989. During the 1980 s, the Chinese government pursued a relatively concessionary policy and responded to Tibetans' dissatisfaction with Chinese rule by reducing rather than increasing the Chinese presence in Tibet.

The second purpose reflects an economic development objective, as indicated by the professional composition of those who have been moved to Tibet. The Chinese government views the lack of educated and technical personnel in Tibet as one of the major reasons why the region has lagged behind economically. Whether this view is accurate is beyond the scope of this article. ${ }^{17}$ The point here is that political control was not the sole motive behind the Chinese transfer policy-at least in the 1980s-and the economic development objective probably was the dominant policy goal.

The findings of this article cannot be used to address fully the issue of the presence of Han people in Tibet because of lack of hard data on spontaneous migration and on troops-two issues that have caused tremendous resentment among Tibetans. ${ }^{18}$ However, as I pointed out at the beginning of this article, it is more appropriate to assess the intentions of the Chinese central government toward Tibet by examining its population transfer policy specifically directed toward Tibet rather than examining a nationwide phenomenon such as spontaneous migration. In that regard, the lack of data on troops handicaps our analysis and it should be explicitly recognized that transfer of civilian cadres is only one part of the question of the movement of Chinese into Tibet. Although, as far as civilian cadres are concerned, the presently available evidence suggests that there has not been a conscious policy of population transfer, it should be pointed out that our knowledge of a larger issue - whether the central government uses the 
movement of Chinese into Tibet to achieve the purposes of political control-still remains partial. A more definitive assessment should await the release of all the relevant documents on the subject and data on troops stationed in Tibet, as well as data on the distribution of ranks between Han and Tibetan cadres.

\section{NOTES}

1. Unless otherwise noted, when "Chinese" is used, it means Han Chinese.

2. For a definition of state secrets, see Article 9 of the Law of the People's Republic of China on Preservation of State Secrets (Ministry of Justice, 1990).

3. Personal communications with Jing Jun.

4. See Sun (1987: 54) and Jia and Peng (1989: 58). For sources in English, see Burns (1987). The Chinese nomenklatura further divides cadres into five categories: government officials, Party officials, clerical personnel in non-profit institutions (shiye danwei), managerial personnel in for-profit institutions (qiye danwei), and officials of mass organizations (qunzhong duanti) (see Chen, Zhang, and Yan, 1986: 306).

5. For example, third-category regions are 3,000 meters above sea level; second-category regions are 2,000 meters above sea level.

6. University graduates who are assigned jobs in Tibet and Qinghai receive the same package of benefits, including an automatic salary increase by one grade and the right to return to their original province once they have served for eight years (Ministry of Labor and Personnel and State Nationalities Affairs Commission, 1983: 361). The cadre recall policy seems to apply to Tibet and Qinghai most systematically and centrally. For these two provinces only, the Department of Organization sets forth the number of transferees, the manner of compensation and resettlement in the receiving provinces, and other guidelines. During the past-Mao period, three rounds of transfers out of Qinghai are known to have occurred. The first was in 1979 and involved about 2,200 cadres; the second was in 1981 and involved thousands (the precise figure has not been disclosed); and the third was in 1985 when about 900 cadres were withdrawn (Department of Organization, 1979, 1981; Department of Organization and Ministry of Labor and Personnel, 1985).

7. The variations are probably a function of different hardship classifications. For example, Urumqi and Lhasa belong to the same salary zone, but for cadres working in Urumqi the living cost adjustment is only $26 \%$ of their salary level as compared with $52 \%$ for Lhasa. Urumqi, however, is a first-category region whereas Tibet is a third-category region.

8. For details, see State Council (1985).

9. The Ministry of Personnel implements cadre transfer policies, which means that it is in charge of selecting and assigning cadres and laying down the logistical work for such transferees. The formulation of cadre transfer policies, at least regarding Tibet, belongs squarely to the Party; in particular, the Department of Organization under the Central Committee issued all of the documents that set the timing and defined the scope of transfers.

10. In 1979, a reasonable estimate for the share of political cadres of the total number of transferees is $9.83 \%$. This is derived by assuming that the tenure for technical cadres dispatched to Tibet in 1979 expired in 1983 and that all of them elected to leave at the end of their tenure. 
In 1979, 3,000 cadres were sent to Tibet; in 1983, 2,705 cadres were withdrawn. The difference is taken to consist of primarily political cadres.

11. For a definition of pingdiao, see Ministry of Personnel (1991: 252).

12. This is a narrow definition of cadres. Tuochan literally means being detached from production activity; tuochan ganbu thus refers to cadres who work in bureaucratic, research, and educational institutions, that is, excluding those working in enterprises.

13. These conditions include ill health, family difficulties, mismatches between positions and skills, and so on (Party Committee and People's Government of the Tibetan Autonomous Region, 1980: 123-124).

14. This reflects the differential policy treatment between Tibet and Qinghai. In the case of Tibet, withdrawals do not hinge on the family circumstances or health of the returnees, although they do in the case of Qinghai (Department of Organization, 1979, 1981). Ethnic considerations are most likely a factor in this difference.

15. The figure is derived from assuming that the share of Chinese cadres remained the same at $55.45 \%$ from 1978 to 1981 . This yields the number of Chinese cadres in Tibet in 1981 to be roughly 29,959 , which is then used to calculate the percentage of those who were transferred out of Tibet.

16. I am grateful to an anonymous referee for Modern China for pointing this out to me.

17. Indeed, two Chinese economists have questioned the wisdom of infusing large-scale assistance from the central government as a way to develop the region (Wang and Bai, 1991).

18. There is no information on the stationing of the People's Liberation Army in Tibet in these documents. It could be plausibly argued that the troops perform political control functions in lieu of Han Chinese cadres. Another issue that cannot be addressed in detail concerns the movement of people into so-called "Greater Tibet," which encompasses not just the Tibetan Autonomous Region (TAR) but all of Qinghai, parts of Sichuan, Yunnan, and Gansu. Apart from Qinghai, there is no documentary evidence in these volumes that there is a systematic and deliberate government policy to transfer cadres to other regions of "Greater Tibet" similar to the one relating to TAR.

\section{REFERENCES}

BURNS, J. (1987) "China's nomenklatura system.” Problems of Communism. (Sept.-Oct.): 36-51.

CHEN ZUYAO, ZHANG ZONGYAO, and YAN JIAMIN [eds.] (1986) Xingzheng guanli zhishi shouce (Handbook of Administrative Management). Beijing: Laodong renshi chubanshe.

Department of Organization [Zuzhi bu] (1979) "Guanyu zuohao Qinghai neidiao ganbu gongzuo de tongzhi" (Circular on smoothly implementing cadre transfer from Qinghai to inland regions), Vol. 4, pp. 116-118 in Ministry of Labor and Personnel (1984).

(1980) "Guanyu zuohao Xizang neidiao ganbu gongzuo de tongzhi" (Circular on smoothly implementing cadre transfer from Tibet to inland regions), Vol. 4, pp. 119-120 in Ministry of Labor and Personnel (1984).

- (1981) "Guanyu renzhen zuohao Qinghai neidiao ganbu gongzuo de tongzhi" (Circular on earnestly implementing cadre transfer from Qinghai to inland regions), Vol. 4, pp. 149-151 in Ministry of Labor and Personnel (1984).

Department of Organization and Ministry of Labor and Personnel [Zuzhi bu he laodong renshi bu] (1983a) "Guanyu wei Xizang xuanpai zhuanye jishu ganbu de tongzhi" (Circular on 
selecting and dispatching specialized technical cadres to Tibet), pp. 357-358 in Ministry of Personnel (1991).

(1983b) "Guanyu Xizang disanpi neidiao ganbu, gongren gongzuo ruogan wenti de tongzhi" (Circular on issues related to the third round of returning cadres and workers to inland regions from Tibet), Vol. 6, pp. 167-171 in Ministry of Labor and Personnel (1986).

- (1985) "Guanyu Qinghaisheng neidiao ganbu anzhi wenti de tongzhi" (Circular on settlement of cadres transferred from Qinghai to inland regions), Vol. 8, pp. 143-145 in Ministry of Labor and Personnel (1986).

- (1987) "Guanyu zuohao Xizang ganbu, gongren neidiao gongzuo de tongzhi" (Circular on smoothly implementing cadre and worker transfer from Tibet to inland regions), Vol. 10, pp. 125-127 in Ministry of Personnel (1988).

Department of Organization and Ministry of Personnel (1988) "Guanyu wei Xizang xuanpai anbu de tongzhi" (Circular on selecting and dispatching cadres to Tibet), pp. 364-368 in Ministry of Personnel (1991).

Department of Organization, Ministry of Personnel, and Ministry of Labor (1989) "Xizang Hanzu ganbu, gongren neidiao, tui (li) xiu hui neidi anzhi gongzuo huiyi jiyao" (Summary of the minutes of the working conference on the settlement of Chinese cadres and workers in Tibet returning to and retiring [terminating work] to return to inland regions), Vol. 12, pp. 226-233 in Ministry of Personnel (1990).

Institute of Sociology [Shehuixue suo] [ed.] (1989) Guanyu Xizang zizhiqu ganbu liudong qingkuang de diaocha (An Investigation into Circulation of Cadres in the Tibetan Autonomous Region). Unpublished paper. Beijing: Institute of Sociology, Beijing University.

JIA ZHAN and PENG JIANFENG [eds.] (1989) Xingzheng guanlixue da cidian (Glossary of Administration Science). Beijing: Shehui kexueyuan chubanshe.

Ministry of Justice [Sifa bu] [ed.] (1990) Zhonghua renmin gongheguo baoshou guojia jimi fa (The law of the People's Republic of China on preserving state secrets), Vol. 1, pp. 181-184 in Ministry of Justice and Bureau of Law of the State Council (Sifa bu he guowuyuan fazhi ju) (ed.), Zhonghua renmin gongheguo xingzheng fagui xuanbian (A Selection of the Administrative Regulations and Laws of the People's Republic of China). Beijing: Falü chubanshe.

Ministry of Labor and Personnel [Laodong renshi bu] (1983) Laodong renshi bu guanyu bianyuan diqu fanwei de tongzhi (Circular of the Ministry of Labor and Personnel on the Zoning of Border and Remote Regions), in Ministry of Personnel (1991).

- [ed.] (1984) Renshi gongzuo wenjian xuanbian (Selected Documents on Personnel Work). Beijing: Laodong renshi chubanshe.

- (1986) Renshi gongzuo wenjian xuanbian (Selected Documents on Personnel Work). Beijing: Laodong renshi chubanshe.

Ministry of Labor and Personnel, and State Nationalities Affairs Commission [Laodong renshi bu, he guojia minzu shiwu weiyuanhui] [ed.] (1983) "Guanyu jiaqiang bianyuan diqu keji duiwu jianshe ruogan zhengce wenti de baogao" (A report on several policy measures to strengthen the team of technical specialists in the border and remote regions), pp. 359-362 in Ministry of Personnel (1991).

Ministry of Personnel [Renshi bu] [ed.] (1988) Renshi gongzuo wenjian xuanbian (Selected Documents on Personnel Work). Shijiazhuang: Hebei renmin chubanshe.

- (1990) Renshi gongzuo wenjian xuanbian (Selected documents on personnel work). Beijing: Zhongguo renshi chubanshe.

(1991) Liudong diaopei gongzuo zhinan (A Guidebook on Cadre Circulation and Transfer Work). Beijing: Gaige chubanshe. 
Party Committee, and People's Government of the Tibetan Autonomous Region [Xizang zizhiqu dangwei, zizhiqu renmin zhengfu] (1980) "Guanyu dapi diaochujin Zang ganbu, gongren de qingshi baogao" (Report concerning the transfer of a large number of cadres and workers into and out of Tibet), Vol. 4, pp. 123-125 in Ministry of Labor and Personnel (1984).

State Council (1985) "Guanyu silei gongziqu tigaodao wulei gongziqu he jifa diqu gongzi banfa de juti" (Detailed provisions for raising the level of the fourth salary zone to that of the fifth salary zone and for calculating salary levels for different regions), Vol. 8, pp. 641-652 in Ministry of Labor and Personnel (1986).

Statistical Bureau of Xizang Autonomous Region [Xizang zizhiqu tongii ju] (1993) Xizang tongji nianjian 1993 (Statistical Yearbook of Xizang 1993). Beijing: Zhongguo tongji chubanshe.

SUN TIE [ed.] (1987) Dangde zuzhi gongzuo cidian (Glossary of Party Organization Work). Beijing: Zhongguo zhanwang chubanshe.

WANG XIAOQIANG and BAI NANFENG (1991) The Poverty of Plenty. London: Macmillan.

Yasheng Huang is assistant professor of political science at the University of Michigan. His articles have appeared in China Quarterly and World Politics. His book, titled The Political Economy of Central and Local Relations in China: Central Investment Policies and Provincial Responses in the Reform Era is forthcoming from Cambridge Univ. Press. He is presently on leave on a SSRC-MacArthur Fellowship and is writing a book on China's economic integration into the world economy. 